\title{
DIAGNÓSTICO DE CÂNCER INFANTIL: UM OLHAR PARA OS SENTIMENTOS VIVENCIADOS PELOS PAIS E RESPONSÁVEIS
}

\section{Gina de Souza Castro Hammel' ${ }^{1}$ Rejane Cassol$^{2}$; Marciele Pinheiro ${ }^{3}$}

\section{RESUMO}

Câncer infantil é a denominação para um grupo de doenças que têm em comum a proliferação descontrolada de células anormais. O câncer infantil representa cerca de $3 \%$ dos tumores na maioria das populações e sua elevada taxa de sobrevida. A figura da família ou responsável pela criança com neoplasias, aparece na cena apenas como pano de fundo ou coadjuvante da história, entretanto, os familiares estão passando por uma situação complicada, quiçá a mais difícil de suas vidas. esse trabalho tem como objetivo descrever os sentimentos vividos pelos pais e responsáveis por crianças com diagnóstico de câncer. $O$ estudo consiste em uma revisão narrativa literatura, com abordagem qualitativa. foram feitas buscas nas bases de dados: LILACS e SCIELO. As palavras-chaves usadas foram: "Câncer infantil"; "sentimentos"; "pais e responsáveis". O Adoecimento da criança, traz mudanças na dinâmica familiar, sentimentos de estresse, medos, ansiedade e impotência.

Palavras-chave: Infância; Promoção de Saúde; Câncerlnfantil.

Eixo Temático: Atenção Integral e Promoção à Saúde.

\footnotetext{
${ }^{1}$ UFN - Mestranda do Curso Saúde Materno Infantil - gina.souza.19@hotmail.com

2 UFN - Mestranda do Curso Saúde Materno Infantil - rejanecassol@hotmail.com

${ }^{3}$ UFN - Mestranda do Curso Saúde Materno Infantil - marcielipinheiro@hotmail.com
} 


\section{INTRODUÇÃO}

Câncer infantil é a denominação para um grupo de doenças que têm em comum a proliferação descontrolada de células anormais e que podem ocorrer em qualquer local do organismo (INCA, 2008). As neoplasias mais frequentes na infância são as leucemias associadas aos glóbulos brancos, tumores do sistema nervoso central e linfomas associados no sistema linfático (Brasil, 2008).

O câncer infantil representa cerca de 3\% dos tumores na maioria das populações e sua elevada taxa de sobrevida garante o status de doença potencialmente curável, cerca de $70 \%$ das crianças (BRASIL, 2008). Apesar desses indicadores, há casos em que o organismo da criança não reage positivamente ao tratamento, tem recaídas ou seu estado agravado. O câncer infantojuvenil é menos frequente quando se compara sua ocorrência em adultos, equivalendo a $2,5 \%$ dos casos (INCA, 2014). Por outro lado, para a faixa etária de zero a 19 anos, no Brasil, o câncer é a segunda causa de morte de acordo com Inca (2014).

A mudança na caracterização do câncer na infância como uma doença crôn ica e não mais aguda e fatal trouxe a necessidade de novos olhares, levando em conta a dimensão psicossocial da doença (VALLE; FRANÇOSO, 1999).

A figura da família ou responsável pela criança com neoplasias, aparece na cena apenas como pano de fundo ou coadjuvante da história, pois a atenção está voltada para a criança acometida com a doença. Entretanto, os familiares estão passando por uma situação complicada, quiçá a mais difícil de suas vidas e muitas vezes seus sentimentos são negligenciados. Nela, estão envolvidos muitos sentimentos como o de impotência, medo, ansiedade de separação, incredulidade e culpa (GRANT, TRAESEL, 2010). Grant; Traesel (2010) frisam que os familiares passam a viver um mundo diferente do seu costume, e passam a viver o mundo da doença da criança, cheio de mudanças e inseguranças.

Brum; Aquino (2014) afirmam que, os indivíduos constituintes da família são independentes, e com o surgimento repentino de uma doença tende a haver uma desestruturação neste meio, sendo necessária a modificação dos papéis exercidos por cada membro. 
Nesse contexto, esse trabalho tem como objetivo descrever os sentimentos vividos pelos pais e responsáveis por crianças com diagnóstico de câncer.

\section{METODOLOGIA}

O estudo consiste em uma revisão narrativa literatura, com abordagem qualitativa. A Revisão Narrativa é uma forma não sistematizada de revisar a literatura. É importante para buscar atualizações a respeito de um determinado assunto dando ao revisor suporte teórico em curto período (BOTELHO et al, 2011).

Para entender os sentimentos dos pais e responsáveis pelas crianças com o diagnóstico de câncer, foram feitas buscas nas bases de dados: LILACS e SCIELO. As palavras-chaves usadas foram: "Câncer infantil"; "sentimentos"; "pais e responsáveis".

A partir dos artigos selecionados fez-se a descrição dos sentimentos encontrados na literatura a cerca do tema.

\section{RESULTADOS E DISCUSSÃO}

Na percepção de Chiattone (1996) o câncer é uma doença penosa que amedronta as pessoas, possuindo, assim, conotações negativas, considerando que seu diagnóstico se dá como uma sentença de morte. Porém, tal percepção é do in ício do século passado, quando receber o diagnóstico de câncer era o mesmo que ser sentenciado à morte. Entretanto, a realidade do câncer, sobretudo o infantil tem mudado pelo aumento da sobreviva, avanço da ciência e tratamentos experimentais.

O diagnóstico de câncer na criança traz dificuldades ainda maiores, pois é mais fácil de se pensar em uma doença grave como esta para adultos, devido a infância ser uma fase da vida que deveria ser de felicidade, brincadeiras e descobertas. $O$ Adoecimento da criança, traz mudanças na dinâmica familiar e essa sofre um impacto sem precedentes, principalmente pela dependência da criança e seu cuidador (GRANT; TRAESEL, 2010). 
De acordo com Françoso; Valle (1999), os familiares e a criança são acometidos por medo e estresse durante todo o processo de diagnóstico e tratamento da criança. $O$ estresse é definido como uma quebra da homeostase interna, ou seja, o equilíbrio interno da pessoa é afetado por alguma situação ou evento no ambiente exigindo esforço para voltar a tal equilíbrio (CODO et al., 2004).

A atuação do psicólogo é considerada de grande importância, estando direcionada em um sentido de ofertar apoio, atenção, compreensão, suporte ao tratamento, clarificação dos sentimentos, esclarecimentos a respeito da doença e fortalecimento dos vínculos familiares (GRANT, TRAESEL, 2010).

O enfoque biopsicossocial, surge como uma compreensão acerca do que vem a ser saúde e doença, buscando oferecer reflexões para adicionar à prática a promoção de saúde mais voltada para o paciente e seus familiares, não somente a patologia. Tais ideias tem ganhado força na formação e na prática dos profissionais de saúde. É importante reforçar que saúde é o total bem-estar biopsicossocial e não somente, ausência de doença (OMS, 1946).

O adoecimento da infantil traz consigo a perda do sentimento de invulnerabilidade da família que agora é ferida no seu sentimento de proteção e imortalidade. Dito isso, é comum observar uma intensa desestruturação familiar, gerando um grande sofrimento acarretado pela angústia de morte. Torna-se necessário ter atenção e cuidado a esses familiares, o que poderá favorecer a recuperação de seu bem-estar, beneficiando inclusive a criança doente (ANGERAMI-CAMON, 2001; FARIAS; CARDOSO, 2006).

Zavarize et al. (2014) comentam que os familiares podem apresentar sentimentos que, por vezes, trazem dicotomias, como "esperança e descrença e ainda desejos inconscientes de morte, justificado racionalmente pelo término do sofrimento."

As mães são as principais responsáveis pelo cuidado da criança, mesmo quando possuem companheiros (SANTO et al., 2011). Viana (2004) e Viorst (2005) colocam que as mães acreditam que sua presença pode evitar que os filhos sofram qualquer mal, assumindo papel de anjo da guarda e escudo protetor. Os autores destacam ainda que a maioria das mães têm pensamentos mágicos de que a sua 
presença protegerá o filho de qualquer tipo de acontecimento, inclusive a morte (VIANA 2004; VIORST 2005).

A observação do sentimento dos cuidadores de crianças com diagnóstico com câncer, mostra que há um sacrifício. Todo zelo, carinho e atenção são fundamentais para uma criança com o câncer, mas é de suma importância olhar para o lado do cuidador que estará sobrecarregado de sentimentos (BOFF, 2000).

O estudo de Faria; Cardoso (2010) traz a luz alguns sentimentos sentidos pelos responsáveis por crianças com diagnóstico de câncer. Sofrimento e dor é o primeiro a aparecer, pois a situação é inesperada e ninguém espera que acontecerá na família. Outro sentimento apontado pelos autores, foi o enfrentamento e buscam principalmente na religião e crença em Deus a força para o momento. Ainda, os entrevistados no estudo de Faria; Cardoso (2010) mostraram que o enfrentamento na busca por tratamento e orientação médica foi muito importante. Em outros casos, o enfrentamento foi através da negação e ainda a comparação com doenças de outros pacientes do hospital.

Os autores identificaram que $50 \%$ dos entrevistados apresentaram indicadores de presença de estresse, sendo que $60 \%$ encontravam-se na fase de resistência. Observaram que já havia presença de estresse instalado e os familiares e acompanhantes se encontravam com menores ou esgotados recursos para lidarem com a exigência da situação (FARIA; CARDOSO, 2010).

O sofrimento dos pais com a doença crônica dos seus filhos resulta em altos níveis de estresse e na ocorrência de sintomas de ansiedade. Estudos relatam que pais de crianças que sobreviveram ao câncer apresentam sintomas de estresse e ansiedade mesmo depois que a criança terminou o tratamento, até mesmo nos casos em que a criança foi considerada curada (KAZAK et al., 2003)

\section{CONCLUSÃO}

Foram abordados nesse estudo alguns aspectos relevantes sobre a temática dos sentimentos vividos pelos pais e responsáveis por crianças com diagnóstico de 
câncer. O diagnóstico de câncer em crianças é sem dúvida um momento doloroso e difícil para todos os envolvidos no contexto familiar.

Observou-se que a maioria dos cuidadores são as próprias mães e elas carregam um turbilhão de sentimentos, principalmente o estresse, ansiedade e sentimento de impotência para o enfretamento do diagnóstico. É importante salientar que o responsável não está preparado para receber a notícia e tal processo o deixa confuso e amedrontado. Ao longo do processo entre diagnóstico, tratamento, cura, recaída ou morte, a rotina diária de paciente, cuidador e família são alteradas e impõe mudança de papéis e adaptações.

Ficou claro que muitos cuidadores buscam na fé a força para enfrentar o diagnóstico da doença e principalmente ao longo de todo tratamento da criança. $\mathrm{O}$ desenvolvimento desse artigo buscou contribuir para o olhar aos pais ou responsáveis das crianças com câncer que por muitas vezes são negligenciados, devido ao fato de todas as atenções estarem voltadas para a criança enferma.

É de suma importância reconhecer e dar suporte objetivando uma melhora na qualidade de vida para o cuidador, sua família e a criança doente.

\section{REFERÊNCIAS}

Brasil. Ministério da Saúde. (2008). Instituto Nacional do Câncer. 2008 de janeiro: Inca.

GRANT, C. H.; TRAESEL, E. S. Vivências de cuidadores de crianças e Adolescentes com câncer: uma reflexão sobre o apoio psicológico. Disc. Scientia. Série: Ciências da Saúde, Santa Maria. 2010.

Institu to Nacional de Câncer “José Alencar Gomes da Silva” (2014). Diagnóstico Instituto Nacional do Câncer (INCA). Coordenação de prevenção e vigilância de câncer. Câncer da criança e adolescente no Brasil: dados dos registros de base populacional e de mortalidade. Rio de Janeiro: INCA; 2008. 
KAZAK, A.E.; CANT, M.C.; JENSEN, M.M.; MCSHERRY, M.; ROURKE, M.T.; HWANG, W.T... et al. Identifying psychosocial risk indicative of subsequent resource use in families of newly diagnosed pediatric oncology patients. J Clin Oncol. 2003.

Organização Mundial da Saúde - OMS. Carta da Organização Mundial de Saúde, 1946.

precoce do câncer na criança e no adolescente (2a ed., rev. ampl., 3a reimp.). Rio SANTO, E.A.R.E., GAIVA, M.A.M., ESPINOSA, M.M., BARBOSA, D.A., BELASCO, A.G.S. Cuidando da criança com câncer: avaliação da sobrecarga e qualidade de vida dos cuidadores. Rev. Latino-Am. Enfermagem. 2011.

ZAVARIZE, N. O., LANG, C. S., TESSARI, D., MAGRI, F., ZOTTO, M. D. A família no processo de cura do câncer infantil a e a atuação do psicólogo hospitalar. II Congresso de Pesquisa e Extensão da Faculdade da Serra Gaúcha, Caxias do Sul, RS, Brasil. 2014. 